\title{
TEACHING ADULTS A FOREIGN LANGUAGE AS PART OF LIFELONG LEARNING
}

\author{
Anna Filatova \\ Assoc. Prof. Dr., Mari State University, Russia, annvit@rambler.ru
}

\begin{abstract}
The article examines the issue of adult education as an important area of pedagogical activity in many countries in the modern world. The development of adult education is caused by rapid changes in technological processes that require highly developed professional knowledge and the ideas of constant personal development.

The article also reveals the features of adult learning. Most adults start learning to solve a problem, not just for fun. This situation is also typical for adults learning a foreign language who begin to master it when they feel the need to do so in order to be more competitive, mobile, flexible and feel comfortable in another country.

The author describes the content, forms and means of teaching a foreign language to adults. Adult learners can be taught a foreign language both in groups and individually. However, adults prefer individual forms of learning a foreign language. The pedagogical value of an individual form lies in the fact that it provides each student with active learning and allows adults to work at their own pace. A teacher gets the opportunity to give adult learners tasks taking into account their individual characteristics, abilities and interests. The opportunity to implement an individual approach to teaching English is provided by Internet resources. Today, teaching foreign languages is impossible without using Internet resources, since they provide us with authentic material and modern study aid for teaching and learning foreign languages. The possibilities of using the Internet resources are multifaceted. The Internet provides adult learners and teachers with all necessary information in a foreign language: country studies, the latest news, articles, necessary educational and fiction literature, reference material, lexical and grammatical exercises on various topics, tests of different levels.
\end{abstract}

Thus, adult education is practice-oriented; adults prefer individual forms of learning a foreign language using Internet resources.

Keywords: adult education, personal development, lifelong learning, foreign languages.

\section{INTRODUCTION}

Currently, adult education is an important area of teaching in many countries around the world. This is due to rapid changes in technological processes that require high professional knowledge. The development of adult education in the world is also facilitated by the idea of constant personal development, continuous learning in various fields of human activity. Adult education is developing both quantitatively by involving an increasing number of people and qualitatively by carrying out research and achieving practical results.

\section{RESEARCH AND RESULTS}

Researchers identify six factors in adult learning:

1. Social relations (to satisfy the need for communication; to find new acquaintances);

2. External stimulus (to fulfill the instructions of the administration; follow the recommendations of an authoritative person);

3. Public welfare (to be more useful to humanity; to be able to take part in social work); 
4. Professional advancement (to get a higher position; to be competitive);

5. Escape (to get rid of the routine of daily life; to provide a contrast to your lifestyle);

6. Cognitive interest (to learn for the sake of gaining knowledge; to satisfy mental needs) (Cross, 1982,300 p.).

According to the research results, professional subjects rank first, housekeeping and family life subjects rank second and subjects related to hobbies rank third. The pragmatism of adult learners is obvious $-3 / 4$ of them choose practical subjects including a foreign language. These data prove the fact that most adults start learning to solve a problem, not just for fun. This situation is also typical for adults learning a foreign language, who begin to master it when they feel the need to be more competitive, mobile, flexible and feel comfortable in another country. Thus, problem-based learning is main in adult education which includes the following steps in the planning of learning process: identifying the problem; awareness of the need to learn; defining goals; identification and finding sources of knowledge. As a rule, adult learners choose the fastest, most easily accessible way of acquiring knowledge because of their employment. The study of a foreign language by adults can take place both in groups and individually.

A number of works by Russian and foreign researchers, such as Ya. M. Kolker (Kolker, Ustinova and Enalieva, 2004, 264 p.), R. Kramsh (Kramsch, 1987, pp. 17-30), H. J. Liimetsa (Liimets, 1975,64 p.), V. Rivers (Rivers, 1981, 576 p.) are devoted to the problem of group learning. So, according to H. J. Liimets (Liimets, 1975, 64 p.), group learning significantly increases the interest of adult learners in educational and cognitive processes.

While teaching a foreign language, various forms of group interaction can be successfully used: work in pairs, in microgroups of three, four, in two teams. With this form of work, communication tasks can be both the same and different for groups. Group work can be organized by involving adult learners in dialogues, problem discussions, press conferences, by creating real situations of communication, problem situations, by playing role-playing and business games.

The use of the game in teaching a foreign language makes the learning process more meaningful and effective, since the game involves everyone in active cognitive activity; play is an activity that gives its participants the opportunity for choice, self-expression, self-determination and self-development; the game creates a comfortable atmosphere in the classroom and increases the desire to study the subject. The game not only develops general educational skills and abilities, but also creates an atmosphere of foreign language communication, establishes new emotional and communicative relationships through interaction, significantly reduces stress of adult learners.

Role-playing games, which are used to simulate real communication situations, are of particular importance for increasing the efficiency of the process of teaching adult learners a foreign language. Role play is aimed at improving foreign language speech skills by participating in imaginary real activities in which the speech behavior of the interlocutors is realized in certain social and communicative roles. Being a model of interpersonal communication, role play contributes to the cognitive activity of adult learners. In a role-playing game, partners take part in active interaction, it involves everyone, without exception, in the activity. By playing certain situations, group members get the opportunity to prepare themselves for a similar situation in real life; role play promotes the formation of learning cooperation and partnership (Konysheva, 2008, 192 p.).

The advantage of role-playing games is that they can be used to study any topic. One example of roleplaying game is the game "The suspect" which is conducted while studying the topic "Appearance". Adult learners receive the following cards:

Student A: You are a police officer. Ask the witnesses questions about the suspect and make detailed notes about him. Make a final description of the suspect.

Student B: You are a police officer's assistant. Listen to the witnesses and draw the pictures of the suspect. Ask the witnesses questions to check that your drawings are correct. Then draw a final picture.

Other adult learners: You are witnesses. Give the police officer a description of the suspect. You have a minute to look at the picture and remember the man's appearance (age, face, skin, hair, clothes, build). At the end of the game, adult learners compare the drawing made with the proposed one.

Investigating the forms of adult learning, the researchers came to the conclusion that the form of traditional learning of a foreign language is not often used by adults. Only $10 \%$ of respondents prefer to work in groups under the guidance of a teacher who plans the entire educational process. 
The choice of the learning form, either individually or in group, also depends on the past learning experience of adult learners. If they did not do well at school, they prefer to study individually and if they studied well, they prefer to attend courses.

Adults prefer to study a foreign language individually for the following reasons:

- Possibility to move at their own pace;

- Possibility to change the direction of training at any time;

- Possibility to start training at any time;

- Lack of time to work in a group;

- Remoteness of the place of training (Cross, 1982, 300 p.).

With an individual form of training, each adult learner performs their task independently. The pedagogical value of this form lies in the fact that it provides an active learning activity for each learner and allows them to work at a feasible pace. The teacher gets the opportunity to differentiate assignments taking into account individual characteristics, abilities and interests of adult learners.

The opportunity to organize individual work in teaching English is provided by Internet resources. The global Internet network provides adult learners with all necessary information in a foreign language. Here they can find regional geographic material, the latest news from leading radio and television companies, articles from newspapers and magazines, necessary educational and fiction literature, reference material, lexical and grammatical exercises on various topics, tests of various levels.

Adult learners can write emails to native speakers, participate in chat rooms, video conferencing, watch videos and foreign films in the original. In addition, more and more adult learners are now seeking to travel abroad for work. To do this, it is necessary to pass international tests, trial versions of which can be passed on the Internet. Having tested their knowledge, adult learners will feel more confident during the actual test.

A huge amount of teaching material on all aspects of a language is provided to teachers and learners of foreign languages on the Internet. Here they can find vocabulary and grammar exercises on a variety of topics, tests of various levels, tasks for reading, writing, listening and speaking.

When learning to read, the Internet is an excellent medium for keeping up with the latest developments in the world. All important mass media in the world have their own web pages. BBC World Service (http://www.bbc.co.uk/worldservice) provides an opportunity not only to read, but also to listen to news in many languages with the opportunity to choose the appropriate level of English proficiency. ABC News (http://www.abcnews.go.com/index.html) accompanies its publications by audio and video. It is also possible to have a conversation on the proposed topic with the readers in the CHAT section. CNN World News (http://cnn.com/WORLD) also provides information in various languages. It is possible to find there audio and video accompaniment. The New York Times offers its readers an educational version of the newspaper with ready-made lessons. News from well-known radio and TV companies can also be found at http://www.washingtonpost.com, http://www.bbc.co.uk, http://www.inopressa.ru, http://cnn.com. Russian news can be found at http://www.gateway2russia.com, the US news can be found at http://www.nytimes.com.

Websites containing news and articles about the world of science may be of particular interest. For example, on the sites http://www.sciencedaily.com, http://www.scientificamerican.com one can get acquainted with the latest developments and discoveries in the field of physics, chemistry, biology, medicine, physics and many other fields of science. On the sites, one can not only read informative articles, get acquainted with the opinions of experts, but also watch videos.

If you need information about facts, phenomena or objects from the scientific, professional, social and everyday spheres of life, you can turn to the website http://www.about.com, where the information is arranged in alphabetical order, starting from accessories and ending with the young generation of adults (young Adults). If you are interested in a specific section, then the information on the site is divided into sections from cars (autos) to video games (video games), each of which is provided with videos, to which the text is attached.

You can find practice tests for passing international exams TOEFL, IELTS, etc., as well as determine the level of language proficiency and find out information about examinations at http://www.examenglish.com, http://www.englishteststore.net. 
The site http://www.englishtag.com is rich in information which contains a large number of tests, quizzes, videos of songs with subtitles, works of famous foreign and Russian writers in English, information about English courses in English-speaking countries. The website http://www.englishclub.com is also educational, where theoretical grammatical material, thematic vocabulary, as well as a variety of grammar and vocabulary exercises are presented. The site contains tasks for all types of speech activity: listening, speaking, reading, writing. For listening, there are records of news from well-known radio and television broadcasters, short stories, fairy tales, poems, songs, interesting facts, which are accompanied by texts and assignments. Here you can also find videos with texts, sections Business English, Games, Quizzes.

You can order fiction and educational literature in English at http://www.englishtip.org. The site http://www.listen-to-english.com hosts audio and video recordings of radio and television programs. The site http://www.native-english.ru places lexical and grammatical tests, oral topics, lyrics, anecdotes, tongue twisters, proverbs, idioms, games, radio texts and films in English with subtitles; text versions of films can be found on the site http://www.script-o-rama.com. On the site http://www.study.ru you can find videos with educational lexical and grammatical material, thematic lexical tests (travel, sports, music), as well as a collection of e-books by English and American writers in English. Http://www.world-english.org provides English language proficiency tests, practice tests for international certification exams, grammar and vocabulary tests, writing and reading comprehension tasks, BBC news videos, CNN and other TV and radio stations.

The site http://www.esl-lab.com places listening tasks of different levels on different topics. On the site http://www.breakingnewsenglish.com you can read or listen to news, information about famous companies and famous people. Each article is presented in several levels of difficulty, which makes it possible to implement an individual approach to teaching adult learners choosing their own level of difficulty for each of them. The information is presented in the form of small notes (about 1000 printed characters) and is accompanied by many tasks: Warms up, Before Reading / Listening (True or False, Synonym Match, Phrase Match, Gap Fill, Guess the Answers), After Reading / Listening (Comprehension Questions), Role-play, Discussion). It is possible to choose a specific set of exercises for a specific group of adult learners. In addition to news, the site posts trailers of famous foreign feature films in English, both modern, for example, The Lone Ranger, Skyfall, and those shot in the second half of the 20th century, such as Back to the Future, The Godfather, each of which is accompanied by tasks.

Thus, the use of Internet resources in teaching English to adult learners allows teachers to implement an individual approach to teaching. The teacher can select tasks that correspond to the level of language proficiency of adult learners. In addition, the use of Internet resources makes it possible to remove psychological barriers and increase adult learners' interest in learning a foreign language, as well as broaden their horizons.

In the process of teaching adults a foreign language, it is necessary to provide them with support in order to make the process of learning a foreign language more enjoyable and less stressful. The level of efficiency of support can be determined with the following system of criteria which reflects both linguistic and personal changes:

1) The level of language knowledge and skills;

2) The level of a positive communicative attitude;

3) The level of sociability;

4) The emotional state of the adult learner as a subject of learning;

5) The level of self-esteem.

Since the implementation of support is carried out in the educational process, adult learners will certainly experience changes at the cognitive level. However, the level of knowledge and language proficiency achieved may vary depending on whether support has been provided or not. Taking into account the peculiarities of the cognitive mechanisms of information processing in a foreign language, the following levels of linguistic training are distinguished:

The initial level of linguistic training. Adult learners have basic skills and abilities, they can translate a text with a dictionary, learn a text on a particular topic, but cannot do creative tasks, are not able to prepare an essay, speech, etc.

A low level of linguistic training. Adult learners are able to process educational material into their own mental content, to master the differences between oral and written forms of speech. 
The average level of linguistic training. Adult learners can work independently with special texts of different types, prepare a dialogue based on a sample, i.e. perform reproductive exercises; are able to work with computer programs, participate in creative cognitive activity.

A sufficient level of linguistic training. Adult learners perform tasks of a creative nature, are able to control their independent activity, expand and deepen the arsenal of linguistic methods of speech-thinking activity in a foreign language, know how to use language knowledge in their specialty, have a sufficiently high outlook on history, culture, literature, art of the country of the target language, etc.

A high level of linguistic training. Adult learners work independently on the Internet sites of various countries, are able to translate literature in their specialty, write reports, scientific articles, develop projects; they speak a fluent foreign language, have developed skills and abilities of independent work, they are able to control their educational activities, actively participate in the educational process, understand the importance and significance of knowing a foreign language.

Learning a foreign language takes place in constant communication and interaction. Therefore, a foreign language is a means of developing communication skills, the level of sociability and formation of a positive communicative attitude.

Researchers of communication process define its functions in different ways. Speaking about oral speech activity in a foreign language in the learning environment, we can say that modeling situations of foreign language communication in the classroom performs an information and communication function. Communication in a foreign language in the classroom should fulfill not only a purely formal function defined by the curriculum and be aimed at mastering the means and methods of foreign language oral communication but also cognitive, educational, emotional, social and other functions that are inherent in communication in the native language. Thus, since learning a foreign language takes place in communication, concurrently, a positive communicative attitude develops and the level of sociability in the native language rises.

The next criterion for evaluating the effectiveness of support is the emotional state of an adult learner. The mental state, being the background on which the life activity of a person proceeds, largely determines the nature of relationships between people, a person's behavior and his activities, including educational ones. The state of a person is situational in many respects. This is, first of all, a reaction to the present, existing situation at the moment.

The mental state can be conditionally divided into favorable and unfavorable. A favorable state contributes to personal development and their productive activities (joy, cheerfulness, interest, confidence, dedication, optimism). An unfavorable state (fear, disappointment, fatigue, resentment) causes a lower range of manifestations of mental processes (thinking, imagination, memory, perception) and a lower productive activity, as a result.

It is very important to maintain a favorable state of a person and contribute to its consolidation as a condition for successful personal development. Through properly organized activities, a teacher can reduce the unfavorable state of adult learners and initiate a favorable one. The adult learner's attitude to learning will depend on which emotions - positive or negative - will arise in an adult learner.

Modern psychology has identified two fundamental positive emotions: interest and joy, which perform a stimulating function in the educational process. Interest is the only emotion which contributes to productive creative activity, has a positive effect on health and is accompanied by the most economical waste of energy resources. Only creative work can give a feeling of joy; the emotion of joy, according to modern data, is the most optimal emotion which contributes to the recovery processes in the body.

The foregoing gives reason to assert that success is possible when a person wants to learn. It is necessary to create an emotionally positive background to make the learning process more comfortable. Uncomfortable conditions prevent from advancement, they cause internal resistance in learners. It is necessary for teachers to take into consideration the fact that resistance they may encounter in the classroom is a kind of defensive reaction of adult learners to a non-standard situation, an unusual role for them. Loss of energy to overcome this resistance, barriers of misunderstanding leads to fatigue, unwillingness to work, anxiety both among the adult learners and the teachers.

We also consider the level of self-esteem as one of the criteria for assessing the effectiveness of support. Self-esteem is viewed by most authors as the core of an individual. It is an internal regulator of behavior, the driving force of personality development. 
The most essential, constituting the essence of self-esteem are individual's ideas about themselves (true self) and what they would like to be (ideal self). Both of these components are socially conditioned. It was the social conditioning of self-esteem that allowed S.L. Rubinstein to write that the attitude of an individual to themselves is always mediated by their attitude to others. Through comparing themselves with the ideal, often through comparing themselves with others, an individual is able to advance in their development (Rubenstein, 1999, 720 p.).

The movement of a person from the past to the present, from the present to the future is a parameter by which a person evaluates themselves. There is, however, another parameter of an individual's self-esteem. Self-esteem also depends on how a person is evaluated by others and how a person reacts to these assessments. All these factors simultaneously determine the content, level and nature of an individual's selfawareness.

Educational process plays a significant role in the formation and improvement of adult learner's self-esteem, therefore, when teaching adults, it is necessary to create conditions for increasing their self-esteem, instill confidence in their capabilities. An individual approach to adult learners, an understanding of the inner world of each adult learner, and the creation of an atmosphere of partnership and mutual assistance are of great importance for solving this problem. It is also important to create an atmosphere in which an adult can express themselves as an independent person and constantly feel their progress.

Adequate self-esteem is the driving force of personality development, the basis for self-actualization. It indicates that an individual understands themselves, sees their own merits and demerits, strives for selfimprovement and self-change, and this is always associated with an individual's ability to self-control.

Inflated or deflated self-esteem is the cause of unfavorable interpersonal relations which adversely affects the psychological climate in the group.

A person who considers themselves much smarter than others and deliberately emphasizes this inevitably irritates others. High self-esteem, showing off, arrogance, disregard for others cause negative reaction of others. On the other hand, low self-esteem leads to excessive dependence on others, shyness, isolation and self-doubt. These personality traits prevent from achieving good results in studies. Thus, only adequate selfesteem can lead to positive results in the learning activity of an adult.

\section{CONCLUSIONS}

Thus, teaching adult learners a foreign language is more successful when both individual and group forms of learning activity are used. The individual form ensures the active learning activity of each adult learner and allows them to work at a feasible pace. Group work contributes to the development of communicative foreign language competencies. According to studies, adults still prefer individual forms of learning a foreign language, but their need for group interaction is expressed quite clearly. To facilitate the process of learning a foreign language, it is necessary to provide adult learners with support by choosing adequate forms, methods, means and content of teaching.

\section{REFERENCE LIST}

Cross, K. Patricia. (1982). Adults as learners. San Francisco: Jossey-Bass, 300 p.

Kolker, Ya. M., Ustinova, E. S. and Enalieva, T. M. (2004). Practical methods of teaching a foreign language: textbook. Moscow: Academy, $264 \mathrm{p}$.

Konysheva, A. V. (2008). Game method in teaching a foreign language. SPb.: Karo; Moscow: Four Quarters, 192 p.

Kramsch, C. J. (1987). Interactive Discourse in Small and Large Groups // Interactive Language Teaching. Cambridge: Cambridge University Press, P. 17-30.

Liimets, H. J. (1975). Group work in the classroom. Moscow: Knowledge, 64 p.

Rivers, W. M. (1981). Teaching Foreign Language Skills. Chicago: University of Chicago Press, 576 p.

Rubenstein, S. L. (1999). Fundamentals of General Psychology: textbook. SPb.: Peter, 720 p. 